\title{
Influence Factors and Model Construction of University Student Cadres Quality
}

\author{
Jian Yong \\ Weihai Vocational College, Shandong, China \\ 1541545319@qq.com
}

Keywords: Influence factors; Model construction; Student cadres quality

\begin{abstract}
At present, there are a lot of researches on student management, but there are few researches on how to improve the quality of universities student cadres. Starting from the angle of improving university student cadre quality, the university student cadre should have a firm political belief, good sense of service, strong communication skills, solid learning foundation and higher management capabilities and other factors constituting the level indicators and secondary indicators and establish the model, using the analytic hierarchy process to analysize the weight of each index and test consistency. Finally, the conclusion is drawn.
\end{abstract}

\section{Introduction}

With the reform deepening of the high education, the scale of universities is becoming larger and larger, the number of universities students is becoming more and more, the quality of students is different, it brings some difficulties to the management of universities students. At present, there are a lot of researches on student management, but there are few researches on how to improve the quality of universities student cadres. Starting from the angle of improving university student cadre quality, the university student cadre should have a firm political belief, good sense of service, strong communication skills, solid learning foundation and higher management capabilities and other factors constituting the level indicators and secondary indicators and establish the model, using the analytic hierarchy process to analysize the weight of each index and test consistency. Finally, the conclusion is drawn. This study provides a reference for the university education administrators, counselors and university students to improve the quality of student cadres.

\section{Build the Model of Affecting the Quality Factor of Student Cadres}

In this paper, the author handed questionnaires to related education administrators, counselors, student cadres and students, then made summary statistics, and finally determined the factors level of the first and second level indicators affecting the university student cadre quality. One class index influence factor of student cadre quality of university students includes strong political beliefs, good service consciousness, strong communication skills, a solid foundation of learning and high management ability.

In the second class indicators:

Political accomplishment includes love motherland, political belief, political learning, theoretical level.

Service consciousness includes servicing social, servicing students, servicing students servicing teacher.

Communication ability includes cooperation consciousness, expression ability, good image, behavior standard.

Learning level includes learning foundation, English level, computer ability and professional ability.

Management ability includes planning ability, executive ability, creative ability, logical thinking. Model Construction is following: 


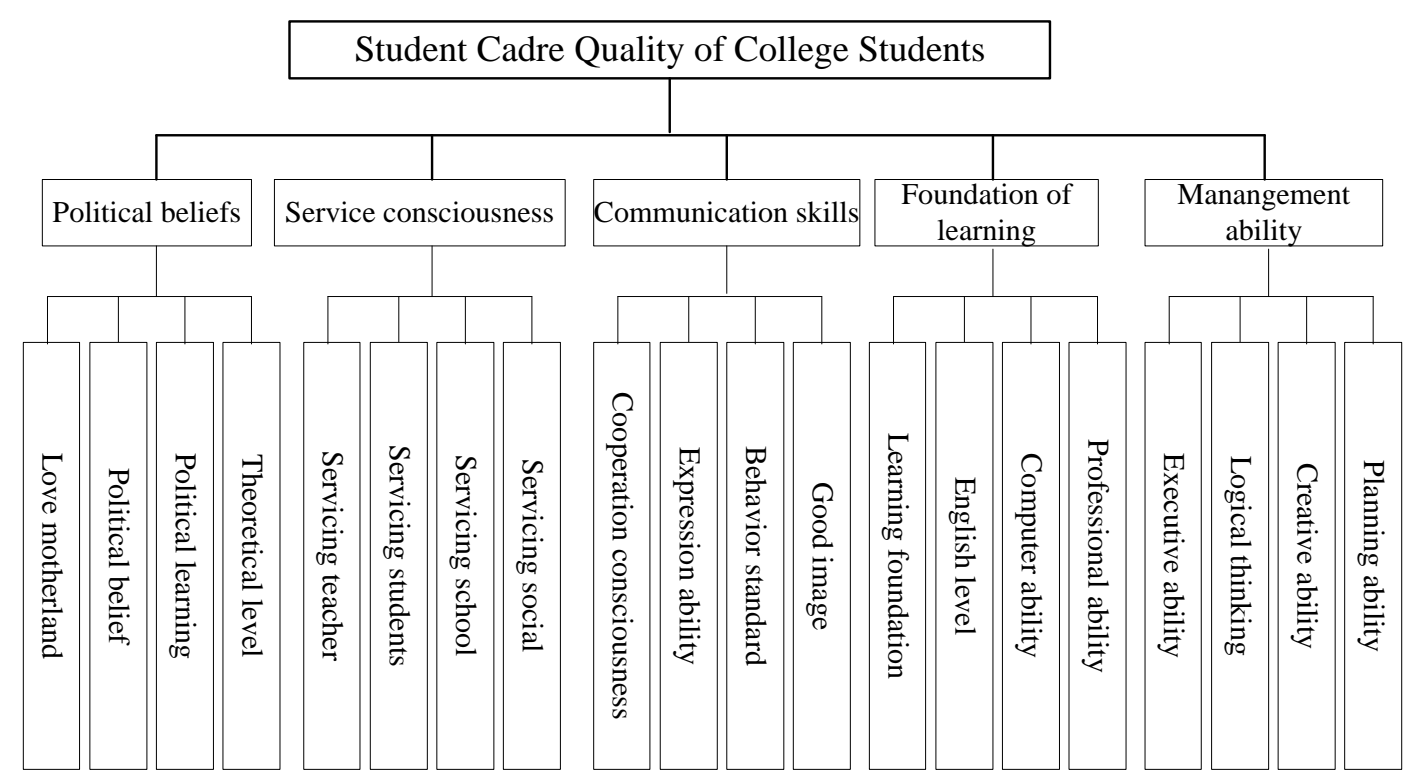

Figure 1. Model Construction of University Student Cadres Quality

\section{Analytic Hierarchy Process}

AHP (Analytic Hierarchy Process) is the elements related to the decision which is always broken down into objectives, principles, scheme. This method is the application theory of network system and multi-objective comprehensive evaluation method, a hierarchical weighted decision analysis method.

\section{Construct Comparison Matrix}

Starting from the hierarchical structure model of the second layer, and the same layer of a layer of each factor factors, Compare 1-9 scaling paired comparison matrix structure, at last calculate weight vector and check consistency. Establish the construction matrix for the first class A0:

$$
\left[\begin{array}{ccccc}
1 & 1 / 5 & 1 / 5 & 1 / 2 & 1 / 6 \\
5 & 1 & 1 / 2 & 3 & 1 / 2 \\
5 & 2 & 1 & 5 & 1 / 2 \\
2 & 1 / 3 & 1 / 5 & 1 & 1 / 3 \\
6 & 2 & 2 & 3 & 1
\end{array}\right]
$$

Weight Vector: $\mathrm{W}=(0.0498,0.2031,0.2968,0.0836,0.3667)$

Check the consistency: ${ }^{\lambda}$ max $=5.1602, \mathrm{CI}=0.0400, \mathrm{CR}=0.0358<0.1$

In the second class, the first factor comparison matrix A1:

$$
\left[\begin{array}{cccc}
1 & 4 & 2 & 2 \\
1 / 4 & 1 & 1 / 3 & 1 / 2 \\
1 / 2 & 3 & 1 & 2 \\
1 / 2 & 2 & 1 / 2 & 1
\end{array}\right]
$$


In the second class, the second factor comparison matrix A2:

$\left[\begin{array}{cccc}1 & 1 / 2 & 2 & 3 \\ 2 & 1 & 3 & 5 \\ 1 / 2 & 1 / 3 & 1 & 2 \\ 1 / 3 & 1 / 5 & 1 / 2 & 1\end{array}\right]$

In the second class, the third factor comparison matrix A3:

$\left[\begin{array}{cccc}1 & 2 & 3 & 5 \\ 1 / 2 & 1 & 2 & 3 \\ 1 / 3 & 1 / 2 & 1 & 3 \\ 1 / 5 & 1 / 3 & 1 / 3 & 1\end{array}\right]$

In the second class, the forth factor comparison matrix A4:

$$
\left[\begin{array}{cccc}
1 & 4 & 3 & 2 \\
1 / 4 & 1 & 1 & 1 / 2 \\
1 / 3 & 1 & 1 & 1 / 2 \\
1 / 2 & 2 & 2 & 1
\end{array}\right]
$$

In the second class, the forth factor comparison matrix A5:

$\left[\begin{array}{cccc}1 & 2 & 6 & 2 \\ 1 / 2 & 1 & 3 & 1 / 2 \\ 1 / 6 & 1 / 3 & 1 & 1 / 3 \\ 1 / 2 & 2 & 3 & 1\end{array}\right]$

In the second class, weight vectors are following:

$$
\begin{aligned}
& \text { A1 }: W(1)=(0.4340,0.0980,0.2856,0.1825), \\
& \text { A2 }: W(2)=(0.2717,0.4832,0.1569,0.0882), \\
& \text { A3 }: W(3)=(0.4792,0.2695,0.1722,0.0791), \\
& \text { A4 :W(4) }=(0.4774,0.1283,0.1378,0.2565), \\
& \text { A5 :W(5) }=(0.4584,0.1927,0.0764,0.2725)
\end{aligned}
$$

Check the consistency:

$$
\begin{aligned}
& \mathrm{A} 1: \lambda_{\max }=4.0457, \mathrm{CI}=0.04004, \mathrm{CR}=0.0169<0.1 \\
& \mathrm{~A} 2: \lambda_{\max }=4.0145, \mathrm{CI}=0.00484, \mathrm{CR}=0.00534<0.1 \\
& \mathrm{~A} 3: \lambda_{\max }=4.0592, \mathrm{CI}=0.01974, \mathrm{CR}=0.02193<0.1 \\
& \mathrm{~A} 4: \lambda_{\max }=4.0104, \mathrm{CI}=0.00345, \mathrm{CR}=0.0038<0.1 \\
& \mathrm{~A} 5: \lambda_{\max }=4.0604, \mathrm{CI}=0.0201, \mathrm{CR}=0.0224<0.1
\end{aligned}
$$

In the first level indicators, the correct political belief is the most important. The student cadres only have good ideology and morality to serve the teachers and students; Having a good service sense can make student cadres not regretted in the work; Strong communication skill is a basic condition; Relatively speaking, solid learning foundation and high management ability are not so important.

In the political literacy, patriotism and loving school are the most important; In the service sense, if the student cadres can service the social, he can serve the students. In communication skills, 
cooperation consciousness rows in the first place; In the level of learning, the foundation of studying is the most important, and in the management ability, planning ability is particularly important.

\section{Conclusion}

University student cadres account for about 20\%-25\% of the total number. In student work, the student cadres take the leading role in leading servicing students, a bridge for communication, between students and the school. As an assistant of teacher and school for students to participate in school organization and management, they are those all the other students management team can't replace.

\section{References}

[1] Discretion and bias in performance evaluation: the impact of diversity and subjectivity Volume [J]:30, Issue: 1, January, 2005, pp.67-78

[2] http://thequalityportal.com/q_ahp.htm. Retrieved 2007-08-21.

[3] European Management Journal Volume [J]: 21, Issue: 3, June, 2003. pp323-337 